\title{
The Role of the University Library in supporting Information Literacy in UK Secondary Schools
}

\author{
Ray Lonsdale \\ Reader in Information Studies, Department of Information Studies, University of Wales, \\ Aberystwyth, UK \\ Chris Armstrong \\ Managing Director, Information Automation Limited, Aberystwyth, UK
}

Purpose - To report on the findings of the CrossEd-2 study, which investigated the role of the university library in delivering information literacy skilling relating to the use of e-resources to secondary schools in the UK.

Design/methodology/approach - A quantitative survey of all university libraries in the UK was undertaken using an e-mail questionnaire to identify the incidence of current collaboration. A return rate of $36 \%$ was achieved, and the data provided information on the types of collaboration taking place in a total of 20 universities. These were categorised and used to select a survey population of six university libraries for the qualitative study. Data collection for the case studies was by means of face-to-face and telephone interviews with university librarians, using semi-structured interview schedules.

Findings - Six forms of collaboration were identified with a range of levels of information literacy skilling evident. Collaboration is characteristically ad hoc, with little involvement of school librarians. The research revealed six distinct positive aspects of cross-sectoral collaboration for school pupils. A fundamental lack of understanding of the respective roles of secondary school and university librarians was demonstrated.

Practical implications - A strategy and a national seminar to enhance collaboration in the UK are discussed.

Originality and value - The first qualitative study that has explored the issues surrounding information literacy skilling relating to the use of e-resources across the secondary and tertiary education sectors in the UK.

Keywords - Information literacy, University libraries, Higher education, Secondary education, School libraries, e-resources

Paper type - Research paper

\section{Introduction}

The genesis of the research study, CrossEd-2, which forms the focus of this paper lies in two earlier pieces of research which the authors had previously conducted during: JISC Usage

Surveys: Trends in Electronic Information Services (JUSTEIS) and CrossEd-1.

\section{JUSTEIS}

In 1999, a Monitoring and Evaluation Framework was established by the Joint Information

Systems Committee (JISC) in an endeavour to discover the degree to which electronic resources 
made available through the JISC were being exploited within further and higher education (HE) in the UK. One of the two studies in the Framework was the JISC User Behaviour in Information seeking: Longitudinal Evaluation of Electronic Information Services (JUBILEE), which sought to predict, monitor and characterise information-seeking behaviour in relation to e-resources, and was undertaken by colleagues at the University of Northumbria in Newcastle (Banwell, 2004). The second study, JUSTEIS, was a longitudinal study of the provision and use of e-resources within colleges and universities, and was conducted with colleagues in the Department of Information Studies of the University of Wales, Aberystwyth (Urquhart et al, 2003).

JUSTEIS was conceived as a series of five annual cycles and comprised two strands. A manual analysis of 190 information and library services (ILS) web sites determined both their structure and the range and number of e-resources offered to all users. A user survey ran throughout the five cycles, using a sampling frame to ensure that both the various types of tertiary education institutions and five disciplinary clusters: pure and applied science; mathematics and engineering; pure and applied social sciences; arts and humanities; and clinical medicine were included in the survey. Over the five cycles, a range of quantitative and qualitative methods were employed; including critical incident technique and critical success factors interviews, which comprised the primary qualitative methodology. This strand surveyed in excess of 130 institutions, and 1,320 students and staff.

A number of worrying issues were highlighted by the research results. In particular, although the web site survey revealed comprehensive provision of a broad array of e-resources, it was clear that undergraduate students in particular were not making use of these. Indeed, to a very large 
extent, their work was found to be dependent on a very narrow array of often inappropriate resources - predominantly search engines and e-mail. Figure 1 , showing data from the $4^{\text {th }}$ cycle, demonstrates clearly this gulf between provision, and use, by undergraduate students. The interviews exposed a high number of students who appear to be ignorant of the more formal eresources, such as e-journals, gateways and databases. Even the more locally-visible resources such as networked CD-ROMs ('Local EIR') were hugely under-exploited.

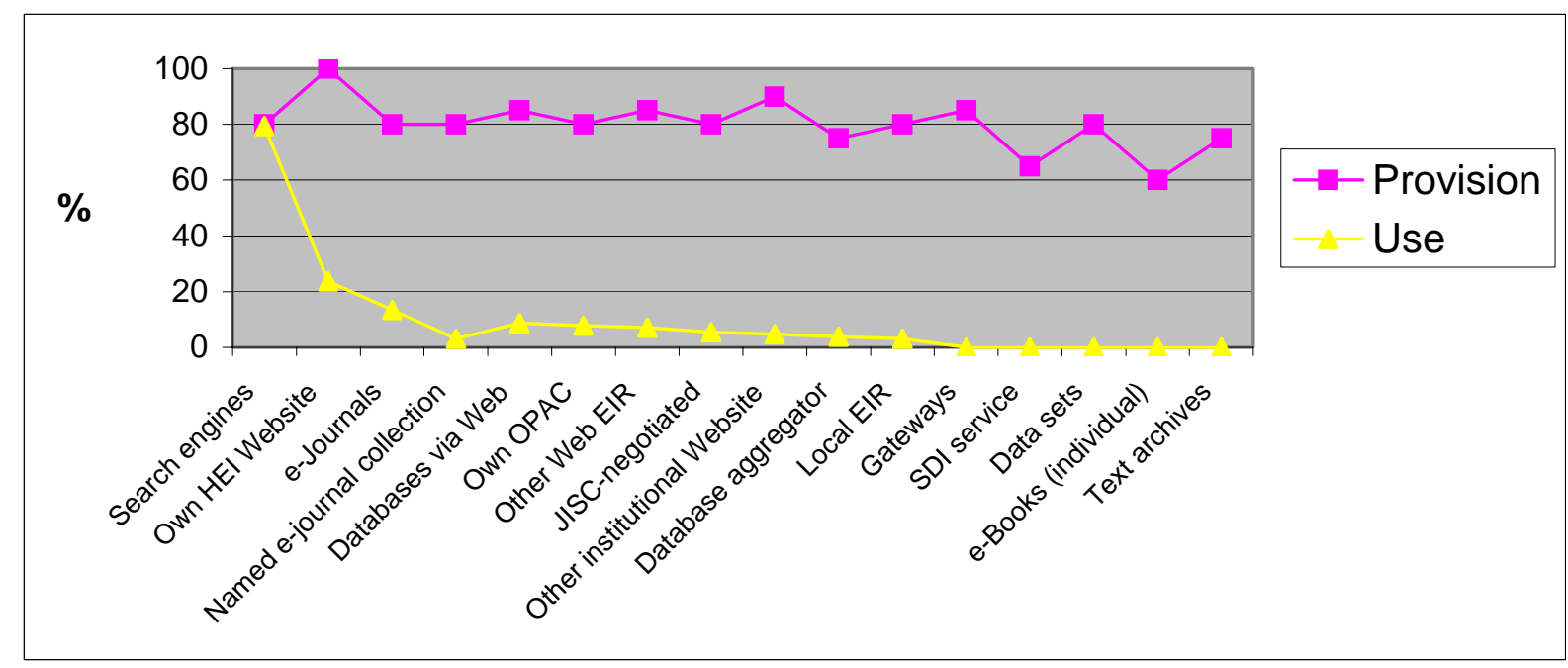

Figure 1: JUSTEIS Cycle 4 comparison of e-resources made available with use by undergraduates

It is clear from the survey that only a low percentage of students consult ILS staff (7.7\%) or attend information skills programmes (7.0\%). A major influence upon students' awareness and use of e-resources are the academic staff (31.5\%), who consequently need to ensure that students are offered structured guidance with clear expectations for academic work. Our research concluded that many students lack the necessary information skills to exploit these resources effectively. 
The results of this longitudinal study suggested to the authors that the students' lack of awareness of e-resources and limited information skills might well be a partial consequence of gaps in training or exposure in the secondary schools sector. This issue was not addressed by the JUSTEIS project but led the authors to develop a working premise that secondary schools may not be inculcating an adequate knowledge and skills base for pupils moving into higher education. It was also felt that cross-sectoral cooperation might benefit students, both while they remain in secondary schools and after they have moved on to university.

\section{CrossEd-1}

In February 2002, the JISC agreed to fund a 9-month study into the possible transferability of knowledge of e-resources and associated information skills from secondary to higher education in the UK (Lonsdale; Armstrong and Eyre, 2002). The study, CrossEd-1, which took cognisance of the different education structures in England, Northern Ireland, Scotland and Wales was initiated in March 2002, and had two aims:

- To investigate information literacy skills development and transfer between the secondary school and libraries in the tertiary education sectors.

- To determine the need for research into literacy transfer and associated areas.

A comprehensive literature search and review, which addressed both of the above aims, demonstrated a clear lack of secondary literature, while official literature comprised the majority of the documentation located. 
An e-mail survey of all libraries in tertiary education was undertaken using three major e-mail lists. This was designed to determine the degree of cross-sectoral collaboration currently taking place in the UK. Given the low response rate from the further education sector, the decision was taken to focus the research upon HE, from which 67 responses were received (41.1\% HE return rate). Data from the questionnaires were entered into Excel for analysis. The e-mail survey was also used to compile a list of 21 library staff willing to take part in the series of structured telephone interviews which comprised the qualitative study. The detailed notes taken during the telephone interviews were analysed manually.

In response to the second aim, to determine the need for research into associated areas, a further survey was undertaken of key government and professional institutions representing ILS, secondary and tertiary education. Following the development of a matrix of organisations across all sectors in England, Wales, Scotland and Northern Ireland, a series of telephone and face-toface interviews with senior representatives of the 80 organisations identified was conducted. Lengthy notes were taken during each interview.

\section{Findings}

Embedded within the literature is a strong case for cross-sectoral activity in the UK. Implicit in Getting on with IT - Post-16 learning strategy (Post 16 E-Learning Strategy Task Force, 2002) was the need to consider the 16 to 19 age group which, by implication raises cross-sectoral issues: "As an immediate first step, the Government should prioritise the following groups when implementing ICT as a basic skill: Young people 16-19 in full or part-time study” (p 14). 
The emerging 14 to 19 agenda emphasised the significance of students working in different educational environments outside of the school and focussed on the importance of individualised learning (Department for Education and Skills, 2002). This agenda also suggests appropriate learning packages with associated skills training are required to satisfy the individual needs of the student. Implicit in this agenda was a requirement for bodies representing the different sectors to explore issues of transferability of skills.

The advantages of secondary and tertiary education working together in a coordinated way to develop information literacy skills across the sectors has been promulgated in several major UK library policy documents. The CILIP publication, Start with the Child, notes:

The development of information literacy skills needs to be synthesized... FE and tertiary education have key roles to play. Approaches need to be co-ordinated and strategies integrated. At present... few colleges have an awareness of how information skills have already been taught to their students. Different approaches at different levels fail to build on past achievements. Until there is a consensus approach, libraries will fail to realise their potential in spreading mass information literacy. (Start with the Child, 2002. 40-41)

The literature appeared to confirm what was initially conjectured: that a logical progression of information skills from secondary education to the tertiary sectors would be appropriate, and that this could be facilitated through cross-sectoral activity. The research was specifically concerned with the strategy skills involved in seeking and exploiting e-resources - information literacy. 
The findings of the HE survey revealed that over half (50.75\%) of the university libraries which responded had some form of link with local secondary schools. Of all those which offered some form of collaboration with secondary education, training in information skills (either general skills or with specific reference to e-resources) was offered to:

- $\quad$ pupils (40\%);

- $\quad$ teachers (28.57\%);

- $\quad$ school librarians (28.57\%).

A variety of different approaches was being taken by university libraries as a part of their work with the secondary sector at that time. The following indicative excerpts from questionnaires reflected their existing concern for, and commitment to, cross-sectoral activity.

"We are currently preparing a research project with X High School Library, Z City Libraries and possibly X Partnership to investigate IT and Internet use by school pupils there which would inform IT and information seeking skills training needs both in school libraries.”

"I am offering a reduced external membership to partnership schools in order to develop links with them. I think it is a very good idea for there to be more communication between schools and HEIs in the area of information skills.” 
In England and Wales, the implementation of the Key Stage $3^{[1]}$ Strategy has had a significant impact upon the development of ICT skilling. The skills are clearly embodied within the ICT and English strands and the teaching and learning framework, and the Strategy should be ensuring that the skills are taught more consistently. However, reservations were expressed by a number of university librarians about the adequacy and nature of the skills. Specifically, the concern was that general ICT skills are embodied in the strands while the more specific information literacy skills receive no attention. Responses such as the following were indicative:

"Schools are much less good at consciously developing information skills"

"I would expect ICT capability but nothing more" ["nothing more" is referring to information skills]

"There is teaching on how to use the Internet and search engines but no underlying skills"

"I doubt if there is an explicit knowledge of information skills, and types of e-resources are not embedded in the list of skills."

The degree to which young people should be equipped with the requisite information skills for tertiary education is not articulated in the Strategy. A number of respondents, in discussing the state of information skills provision in the schools sector, noted that there was little cognisance of

\footnotetext{
${ }^{1}$ UK secondary school education begins at Year 7 (Key Stage 3; age 11 years); Key Stage 4 begins in Year 10 and compulsory education ends in Year 11 (age 16); the $6^{\text {th }}$ form comprises Years 12 and 13 (age 16-18).
} 
need to ensure that the skills base equips children for tertiary education. Examples of children being prepared for the challenges of post-secondary education were cited, however, this was usually dependent upon the initiative of individual teachers.

A final area of interest and potential concern raised by the HE survey was the lack of understanding by librarians in the two sectors of the other's role and the concomitant need to create a mechanism for enhancing professional understanding (Lonsdale and Armstrong, 2004).

The survey succeeded in identifying the existence of collaboration, and issues associated with its value and the problems associated with developing a rapport between the sectors, however, the constraint of time limited the amount of data that could be collected about individual collaborative initiatives.

In addition to the survey of incidence of collaboration, CrossEd-1 collected a considerable amount of data about the need for research into associated fields such as the place of information literacy skills in the initial teacher training curriculum, the provision of e-resources to secondary and tertiary education, and the role of the school librarian in supporting information literacy teaching (Lonsdale and Armstrong, 2004).

Given the absolute absence of published literature on collaboration between university libraries and secondary schools in the UK and the interest and concern generated within all educational sectors and the library profession by the research, one of the recommendations of the report was that there should be further in-depth studies of cross-sectoral activity. 


\section{CrossEd-2}

Following a period of dissemination and discussions on CrossEd-1, the decision was taken to conduct a second phase in summer 2004. CrossEd-2 ran from October 2004 until September 2005, and was designed to explore in greater depth than the previous study the collaborations taking place between secondary schools and university libraries in the UK, and to determine best practice. The aim was to investigate the nature, organisation and value of cross-sectoral activities associated with information skills relating to the use of e-resources.

For each case of collaboration, the objectives were to determine:

- Aims, objectives and rationale of the activity

- Nature and extent of activity

- Which institution initiated the activity

- The staff member(s) responsible for the collaboration within each institution

- Timescale of the activity

- Resource, access and licensing implications of the collaboration for the tertiary institution

- Nature of any evaluation of the activity undertaken by university, college or school.

\section{Methodology}

The study comprised both quantitative and qualitative research. A new quantitative study was conducted to determine collaborations currently taking place, which took the form of an e-mail survey of university libraries. The Society of College, National and University Libraries 
(SCONUL) and the Colleges of Further and Higher Education e-mail lists were used to administer the questionnaire to the tertiary sector. A return rate of 36\% (55 universities) was achieved, and the data from the questionnaire survey were analysed using Excel, in order to categorise the types of collaboration. Twenty-five (43.1\%) of those university libraries working with secondary schools had developed some form of relationship facilitating information literacy skilling. Of these, 20 were willing to take part in an interview as a part of the qualitative study. An analysis of the qualitative data from the questionnaires submitted by these institutions and a range of demographic variables were used to select six institutions that typified the array of collaborations taking place, and these constituted the case studies. The numbers parenthesized below after each quotation from the transcriptions indicate the institution.

Qualitative data collection for the case studies was by means of telephone and face-to-face interviews with the representatives from university libraries. In all instances interviews were conducted with the member of staff who was directly responsible for initiating and organizing collaboration with the schools; and in one instance, the university librarian who was responsible for instigating a policy for cross-sectoral activity also took part in the interview. A structured interview schedule was formulated, piloted and mailed to participants in advance. Interviews were recorded and transcribed for subsequent analysis.

As 18 months had elapsed since CrossEd-1, a new literature search was undertaken and the earlier review was updated. The search revealed no additional UK publications specifically related to cross-sectoral activites, and a very few new titles relating to international developments (e.g. Mittermeyer, 2005; Ellis and Salisbury, 2004). 
The findings presented below have been set out as three inter-related sections: Incidence and forms of collaboration; The role of the school librarian in supporting information literacy; and Organisational and management issues.

\section{Findings: Incidence and Forms of Collaboration}

An analysis of the quantitative data revealed that training in information skills was offered to pupils (60\%); teachers (28\%); and school librarians (16\%). Clearly, collaboration focuses on the pupils and, to a lesser extent, teachers; and scant direct support offered by the university library for school librarians. The latter is particularly significant, in that it portrays a division between two sectors of the same profession - an irony which is discussed below under the role of the school librarian in supporting information literacy.

Six distinct types of collaboration were identified, although it should be noted that in many cases a university adopted more than one approach.

Providing access to e-resources for schools

In its simplest form, collaboration facilitated access to the print or e-resources, and indeed this was shown to be the most prevalent link with schools. The precise nature of access differed between the universities in the survey, and commonly comprised an agreement whereby the school pupils and, occasionally, their teachers were granted external membership. 
Commonly, the context for granting access was seen to be the Widening Participation scheme, which has been in operation in the UK for some years, and which seeks to:

promote and provide the opportunity of successful participation in higher education to everyone who can benefit from it... Widening participation addresses the large discrepancies in the take-up of higher education opportunities between different social groups... [working] with others to raise aspirations and educational attainment among people from underrepresented communities to prepare them for higher education... and give them opportunities to return to learning throughout their lives. (HEFCE, 2006).

In some universities, a Schools Liaison Unit had been established to work with a group of partner schools as part of the Widening Participation scheme, and under this aegis membership would be granted to the schools:

“The Schools Liaison have a Widening Participation group, just a small group, but it’s got a national profile and the work they've done on Widening Participation ...is to make contact with schools which are potential feeders coming into X. They approached us about 6 or 7 years ago to ask if we could contribute to a programme - something on using the library and information retrieval as part of a number of other events that they would be undertaking. We said yes, that's fine, and they really left it up to us to determine what to do." (2)

This response validates a finding relating to Widening Participation from the CrossEd-1 study: "I am offering a reduced external membership to partnership schools in order to develop links with them" 
The issue of defining who may or may not have access to a subscription-based e-resource is primarily governed by the licence agreement. Consequently, there is a potential problem associated with facilitating access to e-resources for schools, as they are, by definition, external users. In those instances where respondents offered membership, it would appear that this is usually by treating either groups or individuals as 'walk-in users', although some university libraries hesitate to accept this interpretation for groups:

“Actually involving a whole group of students, I think that's something that even a walkin access arrangement wouldn't do... I think the walk-in access clauses are targeted at individuals” (2)

Licensors of e-resources are sensitive to the inclusion of non-academic groups, especially those from the business and commercial sectors. However, the library may legitimately argue that school pupils and teachers, whilst constituting an additional user group, do not fall within this sphere:

"Most databases say they are accessible to those who have additional business with your organization. Well, I would include $6^{\text {th }}$ formers amongst those, and clearly they are not in it for commercial gain" (1)

Temporary membership is another possibility, although the licensing agreements for some eresources may not permit this:

"We are moving towards the situation where we will give day passwords to students so they can access those databases and e-journals if they will allow it” (1) 
If the university is running a formal course, such as a Saturday school (see below), then it is possible for the library to register the pupils in order that they may use the licensed e-resources: "If they are registered at $X$ for a course, then they qualify. That's very different from a walk-in visitor who wouldn't get an X log-in. We do have visitor PCs which don't require a log-in and people can use those resources which are allowed through open access.” (3)

\begin{abstract}
Although the university librarians had identified some of the constraints surrounding access, the range of e-resources to which pupils were exposed under licensing agreements is surprisingly broad. The range of formats includes aggregations of e-journals, both bibliographic and full-text databases, and e-books, in particular reference titles. There were, of course, no such constraints in the provision of access to their OPACs, the e-resources section of their web sites and other free eresources.
\end{abstract}

All respondents provided ad hoc information literacy skilling at a variety of levels for pupils in addition to facilitating access to e-resources within the university library collection. The nature of this support was similar to that provided in the university library’s induction programme to undergraduate students, and normally included demonstration of the use and value of the OPAC, guidance about e-resources types, and possibly instruction in developing search strategies.

\title{
Day and summer schools
}

The most common and longest-established types of collaboration in which information skilling occurred were the organized day and summer schools; in some instances these had been in 
existence for almost a decade. The goal of such schools is to offer pupils the opportunity to experience different aspects of undergraduate life. These schools might be established within general programmes associated with Widening Participation or be linked to special events such as National Science Week, and often, programmes would focus on a single subject area. Commonly, the events were targeted at $6^{\text {th }}$-formers and in one case involved over 50 schools.

During such programmes, the university library normally offers a class or classes on information skilling, typically of one to two hours duration. One respondent reported that the course comprised a series of classes at Saturday schools, which were held over the school summer holidays; whilst in other instances, they ran over a single week or weekend. There appears to be a range of different course structures used, even within one university:

“we talk to teachers and teachers are responsible for the induction, the ' $B$ ' model would comprise a little talk from the librarian and then the students are taken up to the library [for a workshop]... there is going to be a 'C' model..." [a subject-oriented model involving collaboration between the History department of the University and the school. This is discussed below.] (4)

The delivery of information skills training differs markedly within the case studies. During the visits access is provided to print and e-resources and, as with the provision of general access, there is frequently individual face-to face support. In some instances, however, a more formal training course was established, which included basic induction training, and also the use of information skills workbooks designed, either by the university library alone or in conjunction with the teachers of the school: 
“They've got a basic information leaflet and then as part of the library session that they actually do here with library staff we have an information skills book which takes them through looking up things in the catalogue, finding things on the shelves and we use Library of Congress classification so that's probably different to what their school uses, they mainly use Dewey, so that's quite different to them. The building's a lot bigger too than school libraries. They have to negotiate their way around the shelves and things like special collections, periodicals, things like that might confuse them so they are given a kind of basic subject guide. That's the guide we would give them to take them through the very basic skills of using the catalogue and where to find things on the shelves." (3)

In other universities, instruction in the use of e-resources commonly addresses the ability to construct strategies for locating information, and the ability to search for and access information. One university librarian had conceived a course within the Saturday schools which offered advanced sessions for gifted children:

"I've done a session with Year-8 gifted and talented, looking at different ways of using the Internet to find information. It has to be Internet-based, it can't be print-based. We talk about search engines where you go if you want to find information, and the pros and cons of using search engines. We also look at things like how a URL is constructed... at that sort of age, it is as much about giving them time to explore so they can start to build their own skills and thoughts about it, as it is about telling them about the various resources. ”(1) 
There is little evidence that pupils are given any training in higher-level information literacy skills such as evaluation, organization and synthesis - as defined by SCONUL and CILIP (SCONUL, 2003; Armstrong et al, 2004). Although it was not a primary objective to investigate the nature of information literacy skilling within the university, data revealed that the majority of respondents who were using or considering the use of the SCONUL model had yet to fully establish training for the higher levels with their undergraduate students. Consequently, it was not surprising that the courses for school pupils only addressed the lower level skills, although three respondents intimated that they would like to see the collaboration include higher skills.

A characteristic feature of the day and summer schools is the use of student mentors or ‘ambassadors’ - university students who will have visited and developed a rapport with the schools, and who will support the work of the teachers and librarians. In the context of information literacy skilling, the librarian will usually endeavour to ensure that the mentors understand the significance of the library and its role in resource provision:

"Our students are trained to work with young people and accompany them on these visits, and some of them have been coming to the library with these groups for a couple of years, and are very good." (1)

Several respondents noted that informal, and sometimes anecdotal, feedback from both the school and the university library suggests that the courses frequently led to increases in a pupil's use of the library:

"When $6^{\text {th }}$-formers have been here with the tutors, they sometimes come back on their own which is splendid. Sometimes they make themselves known and sometimes they don't; 
we do encourage them to come in in a structured way first because they get more out of it.” (1)

\section{Subject-based collaborations}

Another manifestation of collaboration focused on subject-based initiatives in the fields of sociology, history, and business and management, and typically involved innovative teaching and learning methods designed to introduce the pupil to a broader range of information literacy skills. One case study described a history project:

"a project [has been] agreed with the History Department involving the library, which should make the transition between $6^{\text {th }}$ form and the university better/easier for history students. There will be much more focus upon learning outcomes and the involvement of academic staff and librarians, and there will be formal evaluation.” (4)

The aims of this particular approach are to introduce pupils to the specialist resources relevant to students of history, thus creating a context in which all aspects of information literacy skilling (using the SCONUL model) can be explored; and to expose the pupils to the types of teaching and learning methods that they are likely to experience in university.

In another case study, a subject-based example with similar aims had been conceived for Year-11 pupils who were considering applying for entrance to business and management studies. A comprehensive information literacy skilling programme had been developed to extend their ability to use e-resources. The librarian felt that school pupils, even at $6^{\text {th }}$-form level, are not used to finding keywords and describing searches, or - particularly - to evaluating, synthesizing and 
presenting search results, skills which they perceived were lacking in their $1^{\text {st }}$-year undergraduate students. The programme was designed to use scenarios as a context for a mini-case study of a current international news item:

"We gave them a small presentation before hand, but we tried to keep that to a minimum to make sure there was plenty of time for them to go and do it themselves. But we did talk to them about the best way of finding sorts of information and how to use e-resources...

The sessions offered written instructions about what was expected and how pupils should present the results. Pupils were using searching skills which they felt they had, but the exercise allowed then to refine these skills to answer specific questions in a group setting:

"The students had to work collaboratively with each other to find out answers, or make up opinions, or evaluate websites identified by us, and look at information they were retrieving from the internet with a critical eye and then assimilate that information and feed it back at a plenary session at the end...We changed ...from purely worksheet-based training to something which was more scenario-based. They were looking at a sort of idea of Macdonald misleading the public on the nutritional values of food. A group nominated somebody who would feed back, somebody who would take notes, somebody who would chair their group, and that was quite an exercise for them - it didn't appear that they had been doing work like that in the classroom”. (2)

\section{Developmental training programmes}


In the majority of case studies, training programmes had been designed for $6^{\text {th }}$-form pupils, however in one university, the library had conceived a developmental programme for young people aged 11 to 18, which commenced in Year 7:

"We have a little exercise, we only have a very short amount of time with them which is a bit of an obstacle, or a challenge... We talk about the school library to start with, and then we get them to walk around the library and find out what people do in libraries. They know more or less what libraries have in terms of materials and so on, but just looking at the different sorts of activities people do in libraries and they have a check list and we ask them to add extra comments. They do it when there are lots of students around. They go around in very small groups with either one of their student mentors or school mentors because obviously they can be quite disruptive. We get very good feedback from that.... You don't get a lot at the time because they are overwhelmed by the scale of it. Then we sit them down and talk about what they've seen...

The same students come back in year 8. Before they leave after their year 7 visit we say when you come back and see us next year we'll do some work on the computers. We get them to work with the RDN virtual training suite: [resources] where the language is simpler and the approach is simpler. We get them to work through one of those depending on their subject interest, looking at where you find information and what things surprise them in that process.

It's interesting because they say you would expect to get information from a library and from books but they wouldn't necessarily think to ask their friends or family or from 
magazines. We have quite a high staff/pupil ratio in this. They will have their own mentors and usually 2 library staff working with a group. This can be a group as small as 7 or 8 kids and we go round and work with them to help them think about the information they might be finding. It's information literacy. It's recognising the need for information and the fact that it's not always going to be written down. They will bookmark some websites that they are directed to through the suite, through the tutorials and then go and have a look at some of those." (1)

During Year 10, specific training on the use of electronic databases and other e-resources is offered, in which, following a lecture and demonstration, the pupils are given access to a national database. 'Course Discover' is a database used for choosing courses in Higher Education, and pupils undertake exercises to test their skills in an area of particular interest.

The developmental programme ends with a summer school for $6^{\text {th }}$-formers, during which they are afforded the opportunity to interrogate and evaluate examples of different search engines and subject gateways:

"We talk about search engines, and how nefarious organizations can wrap information up to make it look acceptable. Then we look at the subject gateways through that site from Heriot-Watt: Pinakes and they can choose to look at the gateway for their subject area ... they are absolutely cock-a-hoop because they haven't come across it before." (1) 
During the $6^{\text {th }}$-form programme, which was conceived as a part of the school's study skills induction, teachers, teacher librarians and school librarians were present, a rare instance of the direct involvement of school library staff.

\section{Online information literacy skills packages}

Online information literacy skills packages are increasingly employed by British universities to train students. National courses of instruction on subjects including searching and evaluation, such as Tonic: the online Netskills interactive course developed with the support of the JISC, are also available. The 'Online Tutorials, UK' page of the Information Literacy website ${ }^{[2]}$ lists range of institutional and national packages.

The case studies revealed that in several instances, the librarians appreciated the value of making available these, or - as the preferred approach expressed by respondents - specially-tailored, packages for school pupils:

"One of the things we have developed, where we could support the schools without us doing anything at all, is an information skills tutorial which is freely available to anybody and is on our web pages. As far as I'm aware we've never said to schools that this exists, but it's certainly there for anybody to use if they come to the library web pages" (3)

Although Bournemouth University was not interviewed as a part of this study, one rare UK example of a specialist package created for use by prospective students comes from its School of Conservation Sciences. A Web-based ‘Stepping Stones 2HE’ information skills programme has been developed, the aim of which is to help students become confident, independent learners. 
School pupils are sent the URL ${ }^{[3]}$ of the web site which contains a section about studying at University, including information about study skills, and importantly, the Course Team has provided an introduction to students' studies to help them prepare for the academic demands of university.

\section{Courses for school librarians}

Implicit in the results of the quantitative study and the preceding discussion is the fact that school librarians are largely absent from the planning and delivery of collaborative ventures. Equally, they are rarely the recipients of information literacy skilling. Two university libraries, however, recognized the significance of developing a rapport with their colleagues in the secondary school sector and established training designed to create an awareness of the nature of information literacy skilling within HE. These took the form of ad hoc seminars and sometimes included teachers as well as school librarians:

“We invited groups of teachers to explore the library’s holdings...discuss our information literacy skills programme” (4)

"One of the most successful ventures has been the ad hoc seminars which my staff have held with local school librarians...offers insights into higher education provision and practice” (2)

\footnotetext{
${ }^{2}$ http://www.informationliteracy.org.uk/Resources_By_Sector/HE/Tutorials_uk.aspx

${ }^{3}$ http://www.bournemouth.ac.uk/conservation/steps/howto.html
} 
In the last instance, the course was conceived in cooperation with the local School Library Association Committee - a rare acknowledgement of their potential role for effecting collaborations.

\section{Findings: The role of the School Librarian in supporting Information Literacy}

Issues associated with the perceptions which university librarians have of the school's role in information skilling often precipitated collaboration. University librarians believed that schools should be, but are not, preparing incoming students with the requisite knowledge of e-resources for tertiary education:

"I think it would certainly be useful for us to know what type, and what level, of skills students were likely to be coming in with as a result of changes in the school curriculum; and we don't really know much about that." (2)

However, respondents felt that school librarians in England and Wales were experiencing problems similar to themselves in their endeavours to develop information literacy within the school (given developments in integrating information skills within the curriculum in Northern Ireland and Scotland, this view would not be valid across the UK):

"From the conversations I've had with school librarians, and also seeing what they are being asked to do through job adverts, I would have thought that most school librarians are covering information literacy probably throughout the school or that is certainly the intention. How much they are able to achieve I don't know. It's whether they've been able to bring Heads of Department on board to see if it can be integrated into the curriculum. They suffer from many of the same sort of problems that we do. Getting the teachers to 
actually see the relevance, and the fact the librarian has a role in [information skilling], because I still think that is something we fight against with teachers.” (1)

There was also a suggestion that university and school librarians have different ideas of the information literacy skill levels that need to be imparted. This may be a reflection of the lack of communication between library staff in both sectors, and a failure to understand their respective roles in supporting information literacy, as is demonstrated by some questions posed by case study respondents:

- How much do school library staff know about e-resources?

- How much do school library staff know about the nature of provision in universities?

- Why aren’t school library staff doing more information skills training?

One university librarian suggested that school librarians may have only a minor role to play in delivering information skilling:

"But I think we have to get the school librarians talking about information literacy and making sure that we can make appropriate the [work] that they do.” (5)

Given the significant evidence in the literature on information literacy within secondary schools, this is a view to which many school librarians might take exception, and which they may believe is another manifestation of the gulf that exists between the sectors. The following questions drawn from responses made by university librarians demonstrate that there is a belief that such a gulf exists, and that there should be a closer rapport between the sectors:

- How can communication between the school and university sectors be improved? 
- What are the most effective ways for the school and university library to co-operate?

\section{Findings: Organisational and Management Issues}

The study was conceived to explore the various issues associated with the organization and management of cross-sectoral activities. With respect to the ways in which collaboration are initiated, it is evident that while some liaisons came about as a consequence of formal programmes such as Widening Participation, most were a result of personal and informal initiatives on the part of the university library staff. For example, one of the librarians was a school governor and another was married to a head teacher of the school concerned. There was little evidence of a cohesive policy framed within universities, schools or education authorities upon which ongoing programmes of collaboration might have been developed.

A range of individuals from across a university and within one or more schools will normally participate in the planning and organization of visits, especially day and summer schools:

"We've got people at [senior subject librarian] level invited to Faculty Boards for Teaching and Learning, and that can quite often be where these issues come up. In fact this week my Faculty Board, which is Joint Sciences and Life Sciences, had a meeting on school liaison and what they are doing, plus a suggestion for an annual science day." (4)

Frequently, the course or subject teachers, or the head of the $6^{\text {th }}$ form, would be involved, but significantly, there would be no participation by the school library staff. One librarian highlighted two potential issues, which account for lack of involvement of school librarians: 
"I personally am a strong believer that the school librarian ought to be delivering

information literacy ... We certainly try and work with school librarians. Of course it is almost impossible to get them out of their school libraries - being one man bands. I think it's a real issue because I don't think they have the status in the schools that they ought to, to give them the time to do things." (5)

Formal evaluation by university librarians of the information skilling courses was not evident in any of the case studies - and respondents indicated that this was as a consequence of lack of time and resources rather than a reflection of need. One university librarian called for evaluation, and suggested that any such evaluation should be coordinated. It is particularly surprising to note that the university library activities which constitute a part of Widening Participation appear not to be monitored or evaluated as a part of that scheme. Given the potential impact of this skilling on the development of information literacy programmes within the school and its contribution towards raising the perceptions of pupils about university life, the lack of evaluation is of especial concern. Equally, there is no evidence of any formal feedback from schools.

\section{Conclusions}

Whilst only a small incidence of information skilling across the school and university sectors in the UK was identified in the research, the study revealed that collaboration is viewed in a positive light. A variety of types of collaboration exist, which are characteristically ad hoc, arise as the result of informal liaisons with schools, are not evaluated, and focus on lower level skills, although some innovative practice was in evidence. There is little evidence to suggest that the programmes conducted by the university libraries influence the development of an information 
literacy programme within the schools. The existing study was conceived to investigate the nature of collaboration within the university sector and, because of restraints in time and resources, it was not possible to extend it to embrace perceptions held within the schools. It is felt that this is an area worthy of further research.

The study revealed that university librarians are strongly of the opinion that collaboration offers a range of benefits for the pupils. Some benefits pertained to the general orientation of the prospective student to the educational processes to be encountered in undergraduate life, others relate specifically to increased knowledge of e-resources and the acquisition of associated information literacy skills. In summary, collaboration is seen to:

- facilitate enhanced performance in the school

- familiarise pupils with teaching and learning methods adopted in tertiary education

- expose pupils to large resources of the university sector

- encourage pupils into tertiary education

- ease the psychological stress of moving from secondary education to tertiary education

- offer pupils entering tertiary education a more level playing field if some instruction in the use of e-resources were done in school

Further benefits were discernable from the analysis of collaborations, which relate to the university, and in particularly to the library. Greater and more appropriate use of e-resources in undergraduate and postgraduate education would be facilitated. University library staff involved in the collaborations will gain a better understanding of the needs of new students, and, in general terms, there is a discernable improvement in public relations between the two educational sectors. 
Given that the nature of collaboration is ad hoc, it is not surprising that respondents expressed the need for a coherent national policy to address cross-sectoral needs. In 2002, CILIP published the Advisory Group Report on a National Information Strategy (CILIP, 2002). Start with the Child, published the same year, described the Strategy as identifying "the need for an increased focus within the library sector on information literacy as part of a National Information Policy” (Start with the Child, 2002. 41). However, the policy appears to have had very little influence on the development of cross-sectoral activities, and there remains considerable ignorance on the part of both the school and university library sectors as to the nature of information skilling within each other's establishment, and to their respective roles in supporting pupils.

The CrossEd-1 study revealed that, with respect to cross-sectoral activity and information skills development:

"Interviewees emphasized that many of the problems and issues which need to be addressed are a reflection of uncoordinated thinking and planning within and across the different sectors, and confirmed that ... a holistic approach [is required].” (Lonsdale, Armstrong and Eyre, 2002 p.23)

Conclusions drawn from the CrossEd-2 interviews again confirm that a more 'joined-up’ approach for bringing together the various parties would seem to be called for - a strategy that may transcend CILIP's National Information Strategy. At present, although there is an acknowledgement of the potential importance of cross-sectoral activity, national agenda do not appear to address information literacy skilling within and across these sectors, nor do they act as 
a catalyst to cross-sectoral collaboration. Although there is no government agenda per se, individual initiatives are evident. The recent CILIP Community Services Group Information Literacy Group (CSG-ILG), established for representatives of all sectors to exchange knowledge and experience, facilitates the engagement of the school and universities. It is also responsible for the Librarians Information Literacy Annual Conference (LILAC) ${ }^{[4]}$, initiated in 2005, which has provided a rare forum for several papers on delivering information literacy through cross-sectoral collaboration (Secker and Bell, 2005). A further initiative comes from the JISC, which is now exploring cross-sectoral activities with respect to e-resource provision.

Given the demonstrable need for a bringing together of the school, university and library sectors, one suggestion which was voiced by the majority of respondents - and with which we would concur - is that a national seminar dedicated to the transfer of information skilling 'across the gap' is convened.

\section{References}

Armstrong, C., et al (2004), "Defining Information Literacy for the UK”, Library + Information Update Vol. 4 No. 1-2, pp.22-25. Available: E-LIS http://eprints.rclis.org/archive/00006087/ (09/05/2006).

Banwell, L., et al (2004), “The JISC User Behaviour Monitoring and Evaluation Framework”, Journal of Documentation Vol. 60 No. 3, pp.302-320.

CILIP (2002), Policy Advisory Group Report on a National Information Strategy. London: Chartered Institute of Library and Information Professionals.

Department for Education and Skills. (2002), 14-19: Extending opportunities, raising standards: Consultation document. London: DfES. Available: http://www.dfes.gov.uk/1419greenpaper/download/raisingstandards.pdf (21/04/2006).

Ellis, J. and Salisbury, F. (2004), "Information literacy milestones: building upon the prior knowledge of first-year students”, Australian Library Journal Vol. 53 No. 4, pp.383-396.

HEFCE (Higher Education Funding Council for England) (2006), Widening Participation. Available at http://www.hefce.ac.uk/widen/ (20/04/2006).

\footnotetext{
${ }^{4}$ LILAC papers from the 2006 conference will be published in the first issue of the Journal of Information Literacy (October 2006)
} 
Lonsdale, R. and Armstrong, C. (2004), "Crossing the Educational Divide: Issues surrounding the provision and use of electronic resources in secondary and tertiary education”, In P. Moore, E. Howe, R. Lonsdale, R. McCahon and D. Singh (eds). From Aesop to e-book, the story goes on... Selected papers from the $33^{\text {rd }}$ Annual Conference of the International Association of School Librarianship and the $8^{\text {th }}$ International Forum on Research in School Librarianship. Dublin 1720 June. 2004. Erie, PA: International Association of School Librarianship. pp. 60-72. Available: E-LIS http://eprints.rclis.org/archive/00005988/ (09/05/2006).

Lonsdale, R.; Armstrong, C. and Eyre, G. (2002), Report to the Joint Information Services Committee on the Scoping Study into the Transferability of Knowledge and Use of Electronic Information Systems between the Secondary Education and Further and Higher Education Sectors in the UK. London: JISC.

Mittermeyer, D. (2005), "Incoming first year undergraduate students: How information literate are they?” Education for Information Vol. 23 No. 4, pp.203-232.

Post 16 E-Learning Strategy Task Force. (2002), Get on with IT: The Post 16 E-Learning Strategy Task Force report. London: Department for Education and Skills.

SCONUL (2003), Information Skills in Higher Education: A SCONUL Position Paper. Available at http://www.sconul.ac.uk/activities/inf_lit/papers/Seven_pillars.html (24/04/2006).

Secker, J. and Bell, M. (2005), “The Librarians’ Information Literacy Annual Conference (LILAC 2005) at Imperial College 4th-6th April 2005. Organised by CILIP Community Services Group - Information Literacy and supported by ASSIGN", eLucidate Vol. 2 No. 3, pp.2-5.

Start with the child (2002), Start with the child: Report of the CILIP Working Group on library provision for children and young people. London: Chartered Institute of Library and Information Professionals.

Urquhart, C., et al. (2003), "Uptake and use of electronic information services: trends in UK higher education from the JUSTEIS project”, Program Vol. 37 No. 3, pp.168-180.

\section{Biographical Details}

Chris Armstrong is Managing Director of Information Automation Limited (IAL), a consultancy research and training company in the library and information management sector. He works with the Department of Information Studies in Aberystwyth and currently is involved with the management of several research projects and is Module Coordinator for a course on electronic publishing. Contact: lisqual@cix.co.uk

Ray Lonsdale is a Reader in Information Studies in the Department of Information Studies, University of Wales, Aberystwyth, where he is responsible for teaching and research in the fields of children's and schools librarianship and collection management. He has published widely in the field, and was Editor of The School Librarian until 2005. Contact: rel@aber.ac.uk

(c) Emerald Group Publishing Limited, http://www.emeraldinsight.com/info/journals/ap/ap.html 